Eur J Clin Chem Clin Biochem

1995; 33:721-725

(c) 1995 Walter de Gruyter \& Co.

Berlin · New York

\title{
HDL Apolipoprotein A-I Attenuates Oxidative Modification of Low Density Lipoprotein: Studies in Transgenic Mice
}

\author{
By Tony Hayek, Judith Oiknine, Gertrude Dankner, J. Gerald Brook and Michael Aviram \\ Lipid Research Unit, Rambam Medical Center, The Bruce Rappaport Faculty of Medicine, Technion-Israel Institute \\ of Technology and the Rappaport Family Institute for Research in the Medical Sciences, Haifa, Israel
}

(Received March 6/June 16, 1995)

Summary: Epidemiological evidence suggests that plasma high-density lipoprotein (HDL) is protective against coronary artery disease, whereas oxidatively modified low density lipoprotein is atherogenic. Human apolipoprotein A-I transgenic mice with overexpression of the human apolipoprotein A-I gene have increased plasma levels of apolipoprotein A-I and HDL-cholesterol. We analyzed LDL oxidation by determination of LDL associated malondialdehyde, peroxides and conjugated dienes. The present study demonstrates that HDL from both normal and human apolipoprotein A-I transgenic mice at similar concentrations inhibits LDL (protein concentration 500 $\mathrm{mg} / \mathrm{l}$ ) lipid peroxidation, but the effect of the human apolipoprotein A-I transgenic mice HDL was two-fold greater than that of HDL derived from normal mice. In addition, the electrophoretic mobility of oxidatively modified LDL was reduced about two-fold in the presence of human apolipoprotein A-I transgenic mice HDL than that obtained in the presence of normal mice HDL. We thus suggest that human apolipoprotein A-I possesses antioxidant properties which might neutralize LDL lipid peroxidation. This may underline the mechanism responsible for the lower prevalence of atherosclerosis in subjects with high plasma levels of HDL and apolipoprotein A-I.

\section{Introduction}

Epidemiological studies have shown an inverse relation between plasma HDL cholesterol levels and coronary artery disease (1-4). However, the underlying mechanisms responsible for this protective action of $\mathrm{HDL}$ are not yet well established. The most widely accepted hypothesis is that HDL facilitates reverse cholesterol transport $(5-8)$, but other mechanisms, such as the protective effect of HDL on vessel wall and the possible effect of HDL on the atherogenic apolipoprotein B containing lipoproteins, may also be important (9).

Several lines of evidence suggest that LDL oxidation contributes to atherosclerosis $(8,10,11)$. Oxidatively modified LDL is taken up by macrophages at an increased rate in comparison to native LDL, and thus, can promote cellular cholesterol accumulation and foam cell formation, the hallmark of early atherosclerotic lesions $(12,13)$. Possible HDL-mediated inhibition of LDL oxidation may be an additional mechanism by which HDL might protect against the atherosclerotic process in addition to its role in reverse cholesterol transport.

Recently, the transgenic mouse model with overexpression of the human apolipoprotein A-I gene has been described $(14,15)$. These animals have increased levels of apolipoprotein A-I and HDL-cholesterol, which, in turn, may be responsible for their resistance to atherosclerosis. Rubin et al. (16) have recently demonstrated that the atherosclerotic lesion is significantly reduced in human apolipoprotein A-I transgenic mice compared to control littermates after 4 months on a high cholesterol diet.

HDL has previously been shown to reduce the cytotoxic effects of LDL when incubated with endothelial cells $(17-20)$. This could be due to the protective effect of HDL against the toxic effect of the lipoprotein (19) or against LDL lipid peroxidation (20).

The present study was undertaken in order to explore the potential protective effect of human apolipoprotein 
A-I against HDL lipid peroxidation by using mice $\mathrm{HDL}$ derived from human apolipoprotein A-I transgenic (HuAITg) mice.

\section{Methods}

Human apolipoprotein A-1 transgenic mice were kindly provided to us by Dr. Jan Breslow, The Rockefeller University, New York, U.S. A. Transgenic mice expressing the human apolipoprotein AI gene have increased plasma levels of human apolipoprotein A-I and HDL cholesterol $(14,15)$. Blood was collected from the retroorbital plexus under anesthesia with ether $(14,21)$ into Eppendorf tubes with $1 \mathrm{mmol} / 1 \mathrm{Na}_{2}$ EDTA. Lipoproteins (VLDL, $\mathrm{d}<1.006$ $\mathrm{kg} / \mathrm{l}$ : LDL, $\mathrm{d}=1.006-1.063 \mathrm{~kg} / \mathrm{l} ; \mathrm{HDL}, \mathrm{d}=1.063-1.210 \mathrm{~kg} / \mathrm{l})$ were isolated from $3 \mathrm{ml}$ of pooled plasma from human apolipoprotein A-1 transgenic mice or from control littermates by sequential ultracentrifugation as previously described $(14,21)$. Human LDL was isolated from healthy volunteers' plasma by the same method. The isolated lipoproteins were dialyzed against $150 \mathrm{mmol} / \mathrm{l} \mathrm{NaCl}$, $1 \mathrm{mmol} / \mathrm{l}$ EDTA, pH 7.4. Plasma cholesterol in lipoproteins was determined by enzymatic methods (14). Human apolipoprotein AI levels were measured by a turbidimetric immunoassay applied for semiautomatic analyzer (22) and protein was measured by the method of Lowry et al. (23).

Plasma concentration of human apolipoprotein A-I in a representative group of human apolipoprotein A-I transgenic mice was $2800 \pm 300 \mathrm{mg} / \mathrm{l}$ compared to mouse apolipoprotein A-I levels of $1500 \pm 200 \mathrm{mg} / \mathrm{l}$ in normal littermates, and plasma HDL cholesterol concentration was $880 \pm 30 \mathrm{mg} / \mathrm{l}$, compared to HDLcholesterol of $490 \pm 30 \mathrm{mg} / \mathrm{l}(\mathrm{n}=8)$ in controls. It was previously shown $(24,25)$ that, in human apolipoprotein A-I transgenic mice, the major plasma apolipoprotein is human apolipoprotein A-I and their HDL pattern is human-like with both $\mathrm{HDL}_{2}$ and $\mathrm{HDL}_{3}$ subfractions (in normal mice only one HDL fraction, which is $\mathrm{HDL}_{2}$, exists).

LDL oxidation was induced after an overnight dialysis of the lipoprotein against EDTA-free phosphate buffered saline. The lipoproteins were then diluted with phosphate buffered saline to a final protein concentration of $0.5 \mathrm{~g} /$. In order to compare the effect of $\mathrm{HDL}$ derived from human apolipoprotein A-I transgenic mice to that of control HDL derived from normal mice on LDL oxidation, human LDL (protein concentration $1500 \mathrm{mg} / \mathrm{l}$ ) was incubated with control HDL or with human apolipoprotein A-I transgenic mice HDL (protein concentration $0.5 \mathrm{~g} / \mathrm{l}$ ) in the presence of $10 \mu \mathrm{mol} / 1$ $\mathrm{CuSO}_{4}$ for $3 \mathrm{~h}$ at $37^{\circ} \mathrm{C}$. Lipoprotein oxidation was terminated by refrigeration and the addition of $1 \mathrm{mmol} / 1 \mathrm{Na}_{2}$ EDTA. The oxidative state of the lipoproteins was assayed by determination of the thiobarbituric acid reactive substance assay (26), the content of conjugated dienes at $234 \mathrm{~nm}$ (27) and lipid peroxide formation using a commercially available kit (CHOD iodide method, Diagnostic ${ }^{\circledR}$ Merck, Darmstadt, Germany) based on the ability of lipid peroxides to convent iodide to iodine (28). Similar analyses were performed on lipoproteins that were incubated under non-oxidative stress (in the absence of $\mathrm{CuSO}_{4}$ ). In addition, the lag time and the kinetics of LDL and HDL oxidation was determined by monitoring the changes measured at $234 \mathrm{~nm}$ in absorbance, observed at room temperature $\left(23^{\circ} \mathrm{C}\right)$ of freshly isolated human LDL (protein concentration $200 \mathrm{mg} / \mathrm{l}$ of phosphate buffered saline), control mouse HDL (protein concentration $200 \mathrm{mg} / \mathrm{l}$ ), human apolipoprotein A-I transgenic mice HDL (protein concentration $200 \mathrm{mg} / \mathrm{l}$ ), mixtures of human LDL and control mouse HDL or human LDL and human apolipoprotein A-I transgenic mouse HDL in the concentrations indicated above, following incubation with $\mathrm{CuSO}_{4}(10 \mu \mathrm{mol} / \mathrm{l})$. Absorbance was recorded every 10 minutes for a period of 3 hours. The effect of HDL from human apolipoprotein A-I transgenic mice or from control littermates on human LDL oxidation was also assessed by agarose gel electrophoresis. This was carried out on $0.7 \%$ agarose gels at pH 8.6 in $0.05 \mathrm{~mol} / 1$ barbital buffer (29), and the electrophoretic mobility of oxidized LDL under the various experimental conditions was measured.

\section{Results}

The susceptibility of human LDL (protein concentration $500 \mathrm{mg} / \mathrm{l})$ to undergo lipid peroxidation under oxidative stress $\left(10 \mu \mathrm{mol} / / \mathrm{CuSO}_{4}\right)$ was analyzed in the presence of $\mathrm{HDL}$ (protein concentration $500 \mathrm{mg} / \mathrm{l}$ ) derived from normal or from human apolipoprotein A-I transgenic mice.

Both human LDL and HDL from normal mice were oxidized when incubated with $10 \mu \mathrm{mol} / 1 \mathrm{CuSO}_{4}$ for $3 \mathrm{~h}$ at $37^{\circ} \mathrm{C}$ (fig. 1). The susceptibility of human LDL to lipid peroxidation was considerably higher than that of the HDL from the normal mice with 2-fold increase in malondialdehyde levels, 11-fold increase in the peroxide content and 4-fold increase in LDL conjugated dienes content (fig. $1 \mathrm{a}-\mathrm{c}$ ). We then tested the effect of HDL from the control mice on the oxidizability of human LDL. The measured lipid peroxidation rate of human LDL that was incubated together with $\mathrm{HDL}$ from the normal mice was $25 \%, 22 \%$ and $28 \%$ lower for malondialdehyde, peroxide and conjugated dienes, respectively, than the expected oxidation, calculated by adding LDL and HDL lipid peroxidation rates (fig. 1a-c).

We next studied the effect of HDL from human apolipoprotein A-I transgenic mice on human LDL susceptibility to lipid peroxidation. The lipid peroxidation rate of HDL from human apolipoprotein A-I transgenic mice was significantly higher $(p<0.01)$ than that of normal mice HDL (see fig. 2, HDL vs fig. 1, HDL). The effect of HDL from human apolipoprotein A-I transgenic mice on human LDL susceptibility to lipid peroxidation was then analyzed. The measured lipid peroxidation of human LDL when incubated together with HDL from human apolipoprotein A-I transgenic mice was $51 \%, 34 \%$ and $54 \%$ lower than the expected lipid peroxidation as calculated by adding the lipoprotein lipid peroxidation rates for malondialdehyde, peroxide and conjugated dienes, respectively (fig. $2 a-c$ ). These results demonstrate that HDL from human apolipoprotein A-I transgenic mice inhibits human LDL lipid peroxidation by about $50 \%$, a 2 -fold higher inhibitory effect on human LDL oxidation in comparison to the effect of HDL from normal mice. Kinetic analysis of $\mathrm{Cu}^{2+}$ induced LDL oxidation revealed similar results, suggesting that both human apolipoprotein A-I transgenic and control mouse HDL not only attenuate the maximal final level of LDL oxidation but also delay the oxidative process of LDL.

The lag time for human LDL oxidation was 48 minutes, whereas, upon incubation of the human LDL with con- 
trol $\mathrm{HDL}$ as well as with human apolipoprotein A-I transgenic mice HDL, the lag time was significantly decreased to 35 and 34 minutes, respectively, again indicating the inhibitory effect of both HDL preparations on LDL oxidation. Of special interest was the finding that, whereas the lag time of the oxidation of control HDL was 46 minutes, on using human apolipoprotein A-I transgenic mice $\mathrm{HDL}$, the lag time was as short as 25 minutes. This latter result suggests that human apolipoprotein A-I transgenic mouse HDL is a more potent antioxidant than control mouse HDL which can be attributed to its higher capacity to undergo lipid peroxidation. A similar pattern was found on calculating the slope of

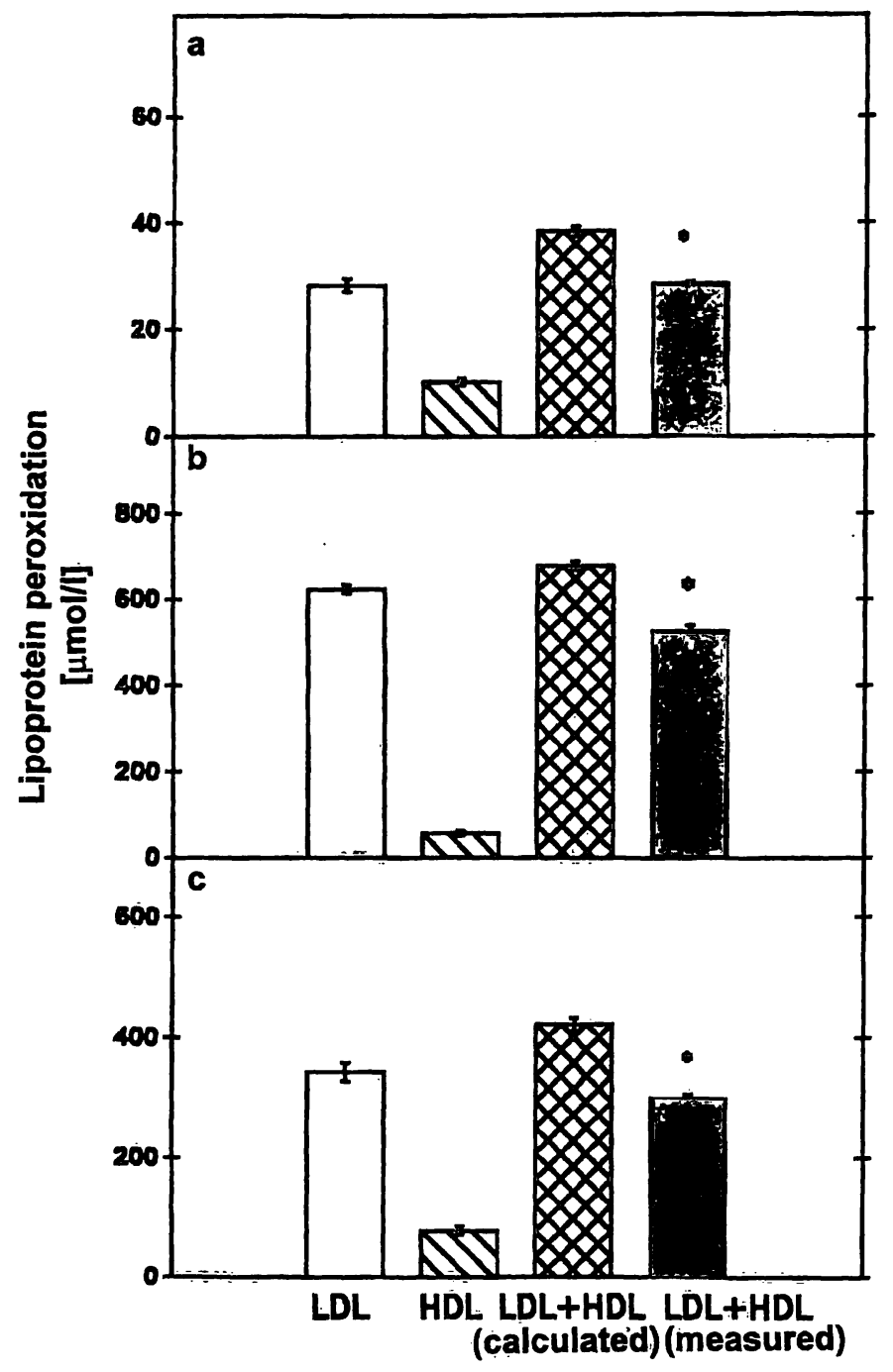

Fig. 1 The susceptibility of human LDL to lipid peroxidation in the presence of HDL from normal mice under oxidative stress $(10$ $\left.\mu \mathrm{mol} / 1 \mathrm{CuSO}_{4}\right)$. Lipoprotein oxidation was carried out by incubation for $3 \mathrm{~h}$ at $37^{\circ} \mathrm{C}$ followed by analysis of malondialdehyde (a), peroxides (b) and conjugated dienes (c). Note that the results for $\mathrm{LDL}$ and HDL alone are expressed as nmol per $0.5 \mathrm{mg}$ lipoprotein protein whereas, for both measured and calculated lipid peroxidation of LDL + HDL; the results represent nmol per $1.0 \mathrm{mg}$ lipoprotein protein. The results are expressed as mean \pm SE of 3 different experiments. ${ }^{*} p<0.01$ (LDL + HDL measured oxidation vs LDL $+\mathrm{HDL}$ calculated oxidation) the propagation phase of LDL oxidation (data not shown).

LDL lipid peroxidation is associated with increased electrophoretic mobility. The electrophoretic mobility of human LDL (protein concentration $500 \mathrm{mg} / \mathrm{l}$ ) was measured following its incubation with HDL (protein concentration $500 \mathrm{mg} / \mathrm{l}$ ) derived from normal mice or from human apolipoprotein A-I transgenic mice in the absence or presence of $10 \mu \mathrm{mol} / \mathrm{l} \mathrm{CuSO}{ }_{4}$ for $3 \mathrm{~h}$ at $37^{\circ} \mathrm{C}$ (tab. 1). LDL lipid peroxidation in the presence of copper ions increased the electrophoretic mobility of native LDL by $30 \%$ (tab. 1a,b). In the presence of HDL from

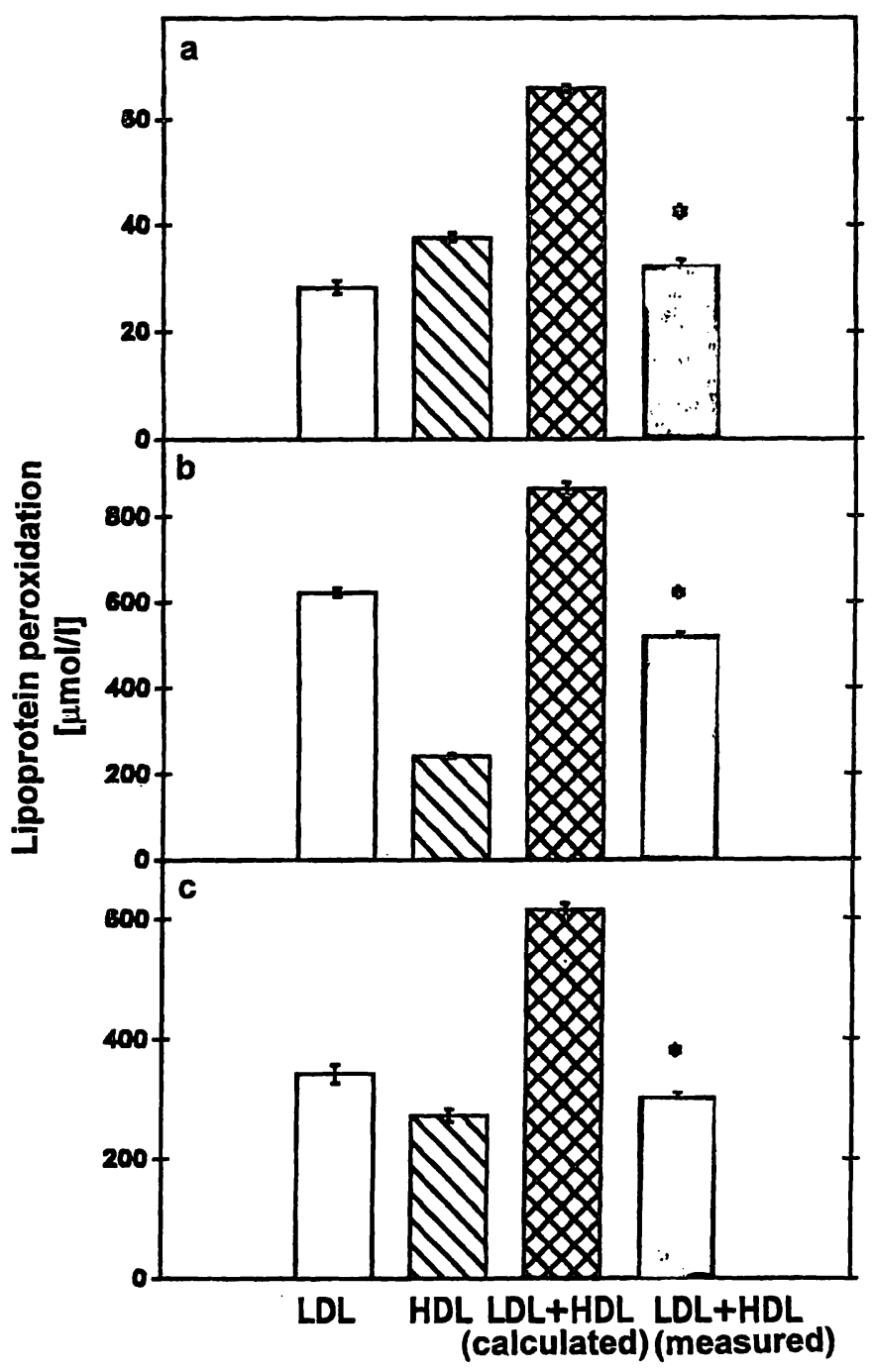

Fig. 2 The susceptibility of human LDL to lipid peroxidation in the presence of HDL from human apolipoprotein A-I transgenic mice under oxidative stress $\left(10 \mu \mathrm{mol} / 1 \mathrm{CuSO}_{4}\right)$. Lipoprotein oxidation was carried out by incubation for $3 \mathrm{~h}$ at $37^{\circ} \mathrm{C}$ followed by analysis of malondialdehyde (a), peroxides (b) and conjugated dienes (c). Note that the results for LDL and HDL alone are expressed as nmol per $0.5 \mathrm{mg}$ liprotein protein whereas, for both measured and calculated lipid peroxidation of $L D L+H D L$, the results represent nmol per $1.0 \mathrm{mg}$ lipoprotein protein. The results are expressed as mean $\pm S E$ of 3 different experiments. ${ }^{*} p<0.01$ (LDL + HDL measured oxidation vs LDL + HDL calculated oxidation) 
Tab. 1 Effect of HDL from human apolipoprotein A-I transgenic mice on the electrophoretic mobility of oxidized LDL

Lipoproteins added

Distance

from the

origin

(cm)

a. LDL

b. $\mathrm{LDL}+\mathrm{CuSO}_{4}(10 \mu \mathrm{mol} / \mathrm{l})$

c. $\mathrm{LDL}+$ normal HDL

d. $\mathrm{LDL}+$ normal $\mathrm{HDL}+\mathrm{CuSO}_{4}(10 \mu \mathrm{mol} / \mathrm{h})$

e. $\mathrm{LDL}+$ transgenic HDL

f. $\mathrm{LDL}+$ transgenic $\mathrm{HDL}+\mathrm{CuSO}_{4}(10 \mu \mathrm{mol} / \mathrm{l})$

$2.7 \pm 0.2$

$3.5 \pm 0.3$

$2.7 \pm 0.3$

$3.1 \pm 0.3$

$2.7 \pm 0.2$

$2.9 \pm 0.3$

The electrophoretic mobility of human LDL (protein concentration $500 \mathrm{mg} / \mathrm{l})$ with or without oxidative stress $\left(10 \mu \mathrm{mol} \mathrm{CuSO}{ }_{4}\right)(\mathrm{a}, \mathrm{b})$ in the presence or the absence of HDL derived from normal $(c, d)$ or from human apolipoprotein A-I transgenic mice $(e, f)$. Results are expressed as mean \pm SE of 3 different experiments.

normal mice, the electrophoretic migration of the oxidized LDL was reduced by only $11 \%$ in comparison to oxidized LDL àlone (tab. 1b,d). The addition of HDL from human apolipoprotein A-I transgenic mice (tab. 1f) further inhibited the migration of human LDL up to $19 \%$ in comparison to oxidized LDL (tabl. 1b). In the absence of copper ions, no effect of either HDL preparation could be found.

\section{Discussion}

Several lines of evidence suggest that plasma HDL levels inversely correlate with coronary artery disease $(1-4)$. The exact mechanism by which HDL protects against atherosclerosis, however, is not known. The inhibitory effect of human apolipoprotein A-I on LDL oxidation may suggest an additional mechanism whereby HDL might attenuate the atherosclerotic process in addition to its well accepted role in reverse cholesterol transport $(5-8)$.

Our study demonstrates that HDL from either normal or human apolipoprotein A-I transgenic mice inhibits LDL lipid peroxidation, but the effect of human apolipoprotein A-I transgenic mice HDL was substantially greater than that of HDL derived from normal mice, suggesting that human apolipoprotein A-I possesses additional antioxidative characteristics.

Matsuda et al. (30) have demonstrated that lipoproteins containing only apolipoprotein A-I (LP A-I) as well as lipoproteins containing both apolipoprotein A-I and apolipoprotein A-II (LP A-I + A-II) are capable of inhibiting LDL oxidation in vitro, but LP A-I was shown to be more effective than LP A-I + A-II. This in vitro model raises the possibility that LP A-I may play a role in protecting $\mathrm{LDL}$ from copper ion-mediated oxidation, as demonstrated in the present study. LP A-I might act by more effectively preventing interaction of apolipoprotein $\mathrm{B}$ with the malondialdehyde formed during the oxidation process than LP A-I + A-II.

Furthermore, Klimov et al. have alṣq demonstrated (20) that HDL possesses antioxidant properties against LDL oxidation in vitro. When $\mathrm{HDL}_{3}$ was administrered intravenously to hypercholesterolaemic rabbits, a decreased ex vivo LDL lipid peroxidation was demonstrated (31), suggesting that HDL, in addition to other antioxidative systems, may take part in the protection of LDL from lipid peroxidation. Klimov et al. demonstrated that $\mathrm{HDL}_{3}$, but not $\mathrm{HDL}_{2}$, inhibits LDL oxidation in vivo and in vitro $(28,31)$. In our study we used human apolipoprotein A-I transgenic mice HDL in which the $\mathrm{HDL}$ pattern is human-like with $\mathrm{HDL}_{2}$ and $\mathrm{HDL}_{3}$ subfractions, compared to HDL from normal mice in which the HDL comprises just one component which approximates $\mathrm{HDL}_{2}$ in size. This may explain the higher capacity of human apolipoprotein A-I transgenic HDL (which contains both $\mathrm{HDL}_{2}$ and $\mathrm{HDL}_{3}$ ) to inhibit $\mathrm{LDL}$ oxidation than HDL from the normal mice.

Breslow et al. recently demonstrated (9) that by cross breeding human apolipoprotein A-I transgenic mice with apolipoprotein E-deficient mice, the plasma HDL cholesterol levels were elevated by 2 -fold in comparison to apolipoprotein E-deficient mice HDL-cholesterol and atherosclerotic lesions were significantly less pronounced (9). Rubin et al. (32) also demonstrated that the apolipoprotein A-I transgene corrects apolipoprotein $\mathrm{E}$ deficiency-induced atherosclerosis in mice. This latter effect may involve HDL-mediating prostaglandin transport (33), as well as the inhibitory effect of apolipoprotein A-I on LDL lipid peroxidation in the arterial wall.

Interestingly, our study demonstrates that the lipid peroxidation of human apolipoprotein A-I transgenic mice HDL is considerably greater than that of normal mice HDL. This higher propensity of human apolipoprotein A-I transgenic mice HDL for oxidation may be related to the mechanism by which human apolipoprotein AI in human apolipoprotein A-I transgenic mice HDL protects against lipid peroxidation of human LDL.

Parthasarathy et al. also suggested that HDL may play a protective role in atherogenesis by preventing the generation of oxidatively modified LDL (34) by a mechanism which involves the exchange of lipid peroxidation products between the LDL and HDL. This mechanism may also operate with apolipoprotein A-I in HDL from human apolipoprotein A-I transgenic mice as demonstrated by its higher oxidizability in comparison to that of normal mice. 
In conclusion, the present study demonstrated that human apolipoprotein A-I possesses significant antioxidative properties against LDL lipid peroxidation, and this may underline the mechanism responsible for the protective effect observed in subjects with increased plasma concentrations of apolipoprotein A-I (4).

\section{References}

1. Castelli WP, Garrison RJ, Wilson PW, Abbott RD, Kalousdian $S$, Kannel WB. Incidence of coronary heart disease and lipoprotein cholesterol levels. J Am Med Assoc 1986; 256:2835-8.

2. Gordon DJ, Knoke J, Probstfield JL, Superko R, Tyroler HA. HDL-C and coronary heart disease in hypercholesterolemic men: the lipid research clinic's coronary primary prevention trial. Circulation 1986; 74:1217-25.

3. Miller NE. Associations of HDL subclasses and apolipoproteins with ischemic heart disease and coronary atherosclerosis. Am Heart J 1987; 113:589-97.

4. Gordon D, Rifkind B. HDL - the clinical implication of recent studies. N Engl J Med 1989; 19:1371-5.

5. Reichl D, Miller N. Pathophysiology of reverse cholesterol transport. Insights from inherited disorders of lipoprotein metabolism. Arteriosclerosis 1989; 9:785-97.

6. Aviram M, Bierman E, Oram J. High density lipoprotein stimulates sterol translocation between intracellular and plasma membrane pools in human monocyte-derived macrophages. $J$ Lipid Res 1989; 30:65-76.

7. Mahlberg F, Rothblat G. Cellular cholesterol efflux. Role of cell membrane kinetic pools and interaction with apolipoproteins AI, AIl and Cs. J Biol Chem 1992; 267:4541-50.

8. Aviram M. Modified forms of low density lipoprotein and atherosclerosis. Atherosclerosis 1993; 98:1-9.

9. Plump A, Scott C, Breslow JL. Human apolipoprotein A-I gene expression raises $\mathrm{HDL}$ and suppresses atherosclerosis in apo E-deficient mice. Proc Natl Acad Sci USA 1994; 91:9607-11.

10. Witztum $\pi$, Steinberg D. Role of oxidized LDL in atherogenesis. J Clin Invest $1991 ; 88: 1785-91$.

11. Parthasarathy S, Steinberg D, Witztum JL. The role of oxidized LDL in the pathogenesis of atherosclerosis. Ann Rev Med 1992; 43:219.

12. Aviram M. LDL modification by cholesterol oxidase induces enhanced uptake and cholesterol accumulation in cells. J Biol Chem 1992; 267:218-25.

13. Aviram M, Dankner G, Brook JG. Platelet secretory products increase low density lipoprotein oxidation, enhance its uptake by macrophages and reduce its fluidity. Arteriosclerosis 1990; 10:559-63.

14. Walsh A, Ito Y, Breslow JL. High levels of human apo A-I in transgenic mice result in increased plasma levels of small HDL particles comparable to human $\mathrm{HDL}_{3}$. J Biol Chem 1989; 264:6488-94.

15. Rubin EM, Ishida BY, Clift SM, Krauss RM. Expression of human apo A-I in transgenic mice results in reduced plasma levels of murine apo A-I and the appearance of two new HDL size subclasses. Proc Natl Acad Sci USA. 1991; 88:434-8.

16. Rubin EM, Krauss RM, Spangler EA, Verstuyft JG, Clift SM. Inhibition of early atherogenesis in transgenic mice by human apolipoprotein A-I. Nature 1991; 353:265-7.

17. Henriksen T, Evensen SA, Carlander B. Injury to cultured endothelial cells induced by LDL: protection of high density lipoproteins. Scand J Clin Lab Invest 1979; 39:69-75.

18. Hessler JR, Morel DW, Lewis LJ, Chisolm GM. Lipoprotein oxidation and lipoprotein induced cytotoxicity. Arteriosclerosis $1983 ; 3: 215-9$.

19. Cathcart MK, Chisolm GM, Morel DW, McNally AK. Monocytes and neutrophils oxidize LDL making it cytotoxic. J Leuk Biol 1985; 38:341.

20. Klimov AN, Nikiforova AA, Pleskov VM, Kuzmin AA, Kalashnikova NN. Protective effect of HDL, their subfractions and LCAT on the peroxidative modification of LDL. Biokhimia 1989; 54:118-23.

21. Hayek T, Oiknine J, Brook JG, Aviram M. Increased plasma and lipoprotein lipid peroxidation in apo E-deficient mice. Biochem Biophys Res Comm 1994; 201:1567-74.

22. Rifai N, King ME. Immunoturbidimetric assays of apolipoproteins AI, AII and B in serum. Clin Chem 1986; 32:957-61.

23. Lowry OH, Rosebrough NJ, Farr L, Randall RJ. Protein measurement with the folin phenol reagent. J Biol Chem 1951; 193:265-75.

24. Chajek-Chaul T, Hayek T, Walsh A, Breslow JL. Human apo A-I expression in transgenic mice alters HDL particle size distribution and diminishes selective uptake of HDL cholesterol esters. Proc Natl Acad Sci USA 1991; 88:6731-5.

25. Hayek T, Chajek-Shaul T, Walsh A, Azrolan N, Breslow JL. Probucol decreases apo A-I transport rate and increases HDL cholesteryl ester functional catabolic rate in control and human A-I transgenic mice. Arteriosclerosis 1991; 11:1295-302.

26. Buege JA, Aust SD. Microsomal lipid peroxidation. Methods Enzymol 1978; 52:302-10.

27. Halliwell B, Guttridge JM. Role of iron in oxygen radical reactions. Methods Enzymol 1984; 105:47-56.

28. El-Saadani M, Esterbauer M, El-Sayed M, Goher M, Nasser AY, Jurgen SJ. A spectrophotometric assay for lipid peroxides in serum lipoprotein using a commercially available reagent. J Lipid Res 1989; 30:627-31.

29. Fong LG, Parthasarathy S, Witztum JL, Steinberg D. Nonenzymatic oxidative cleavage of peptide bonds in apoprotein B100. J Lipid Res 1987; 28:1466-77.

30. Ohta T, Takata K, Horinchi S, Morino T, Matsuda I. Protective effect of lipoproteins containing apo A-I on $\mathrm{Cu}^{+2}$ catalyzed oxidation of human LDL. FEBS Lett 1989; 257:435-8.

31. Klimov AN, Gurevich VS, Nikiforova AA, Shatilina LV, Kuzmin AA, Plavinsky SL. Antioxidative activity of high density lipoproteins in vivo. Atherosclerosis 1993; 100:13-8.

32. Paszty C, Maeda N, Verstuyft J, Robin EM. Apolipoprotein AI transgene corrects apolipoprotein $\mathrm{E}$ deficiency-induced atherosclerosis. J Clin Invest 1994; 94:899-903.

33. Yoshiki Y, Takihsi A, Hiroshi M, Mamoru T, Yoshiki T, Chuichi $\mathrm{K}$. Serum prostacyclin stabilizing factor is identical to apo A-I. A novel function of apo A-I. J Clin Invest 1988; $82: 803-7$.

34. Parthasarathy S, Barnett J, Fong L. High density lipoprotein inhibits the oxidative modification of low density lipoprotein. Biochim Biophys Acta 1990; 1044:275-83.

Dr. T. Hayek

Department of Internal Medicine D

Rambam Medical Center

Haifa 31096

Israel 


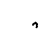

